\title{
The First Example of Cation Radical Induced Desulfurization from Disulfides
}

\author{
Bo Kyung Park and Wang Keun Lee* \\ Deparment of Chemistry Education. Chomam Xatonal Linversity, Gn'ang-/ $500-757$, Korea \\ Received February 21. 2003
}

Key Words : 'Thianthrene cation radical. Disultide, Desulfurization

Over the lasi several years we have discovered cation radical induced oxidative decomposition of azo compounds (cq 1). ${ }^{1.3}$ carbonales (eq 2). ${ }^{1.5}$ carbamates (cq 3). and peroxides (cq +). ${ }^{7}$ It was recognized in those discoveries that carbocationic chemisiry with $\mathrm{C}-\mathrm{N}$ or $\mathrm{C}-\mathrm{O}$ bond cleavages was predominant with the $2: 1$ stoichiometry, two moles of aromatic cation radical and one mole of oxidized molecules in acctonitrile at room temperature.

$$
\begin{aligned}
& 2 \mathrm{Th}^{-\cdot}+\mathrm{R}-\mathrm{N}=\mathrm{N}-\mathrm{R} \stackrel{\mathrm{MeCN}}{\longrightarrow} \\
& 2 \mathrm{RNHCOCH}_{3}+2 \mathrm{Tll}+\mathrm{N}_{2}
\end{aligned}
$$

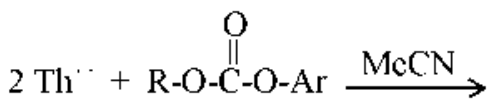

$$
\begin{aligned}
& \mathrm{RNHCOCH}_{3}+\mathrm{Th}+\mathrm{Th}-\mathrm{Ar}-\mathrm{OH}+\mathrm{CO}_{2} \\
& 2 \mathrm{~Tb}^{-}+\stackrel{\text { R-O-C }}{\text { O }} \mathrm{NR}^{\prime}-\mathrm{Ar} \stackrel{\mathrm{MeCN}}{\longrightarrow} \\
& \mathrm{RNHCOCH}_{3}+\mathrm{Th}_{1}+\mathrm{Tl}^{-}-\mathrm{Ar}-\mathrm{NHR} \mathrm{R}^{\prime}+\mathrm{CO}_{2} \\
& 2 \mathrm{Th}^{-}+\mathrm{R}-\mathrm{O}-\mathrm{O}-\mathrm{R} \stackrel{\mathrm{MeCN}}{\longrightarrow} \\
& 2 \mathrm{RNHCOCH}_{3}+\mathrm{Th}+\mathrm{ThO}+\mathrm{SSO}_{2}
\end{aligned}
$$

ln contimuing our work with these oxidative decomposition of disulfide. we have found that thermally stable tert-butyl disulfide is readily oxidized by thianthrene cation radical perchlorate $\left(\mathrm{Th}^{\prime}{ }^{\circ} \mathrm{ClO}^{-}{ }^{-}, 1\right)$ with evolution of $\mathrm{S}_{2}$ in acetonitrile at room temperature. This is a novel reaction of disulfides and offers the first example of cation radical induced desulfurization. Work for desulfurization of disulfides

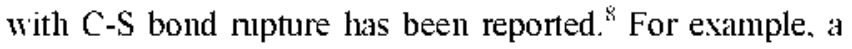
number of natural products contain a cyclic disulfide unit involve the Diels-Alder addition of in sin generated singlet $\mathrm{S}_{2}$ to dienes. In the present study; as the other oxidative decomposition..$^{1-3}$ the major products from the reaction of the disulfide, 2, with 1 are characteristic of tert-butyl cations while the minor ones imply a free sulfur radical component of the reaction. In other words. carbocationic chemistry is observed predominantly from a alkyl disulfide, a source of free radicals. ${ }^{9}$ The major products were 1 -tert-butylacetamide (3) from tert-butyl cation which was isolated in $80 \%$ yield. and thianthrene $(\mathrm{Th}, 95 \%)$ by reducing of $\mathrm{Th}^{\prime}$. Without doubt. tert-butyl cations reacted with the solvent acetonitrile to give a Ritter-type intermediate $\left(\mathrm{Me}_{3} \mathrm{CN}={ }^{\prime} \mathrm{CMe}\right)$, which hydrated during workup. to give 3 . The unexpected dimeriz-

"Correspending author. Tel: +82-62-530-2493: Fax: +82-62-5302499: c-mail: wklew $a$ chomnam.ac.ks

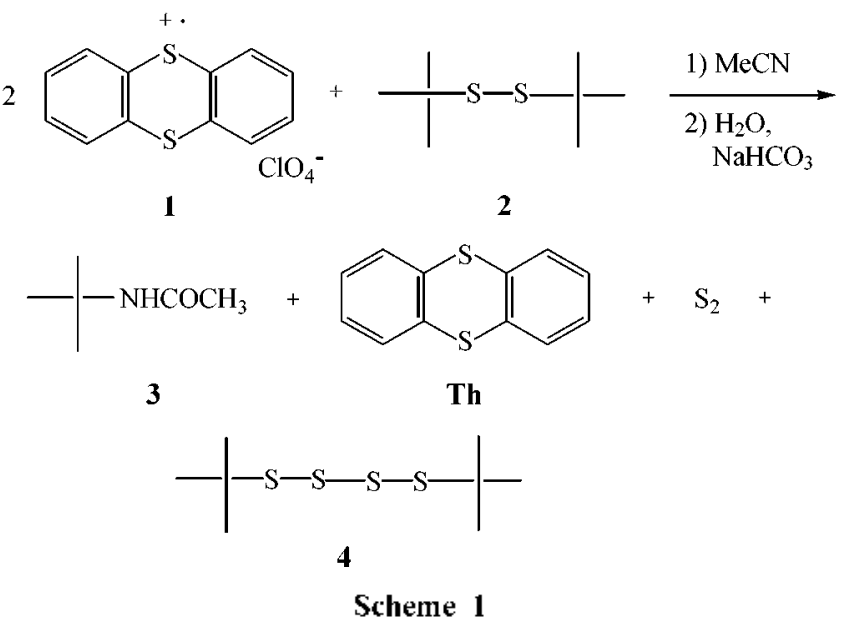

ed product. di-tert-buty] ictrasulfide. $4(10 \%)$. must have becn formed from dimerization of tent-butylperthiy] radical (5. $\mathrm{Mc}_{3} \mathrm{C}-\mathrm{S}-\mathrm{S}$ ). Product balances account for $90 \%$ of the tert-bulyl groups which appears as cations. and $95 \%$ of the cation radicals.

Products obtaincd from reaction of 1 with very stable 2 are shown in Scheme 1 and an explanation of the formation of products is shown in Sclieme 2. The cation radical $\left(2^{+*}\right)$ of tert-buly $\mathrm{L}$ disulfide leads to rapid C-S bond clcavage instead of $\mathrm{S}-\mathrm{S}$ bond nupture at room icmperature 10 give tentbutylperthiyl radical (5) and tert-butyl cation in Scheme 2. The pertliyl madical. 5. cxlibited two subsequent transformations. Major pathway is oxidation of 5 by 1 with great facility to carbocation and crolution of $S_{2}$. Minor one is

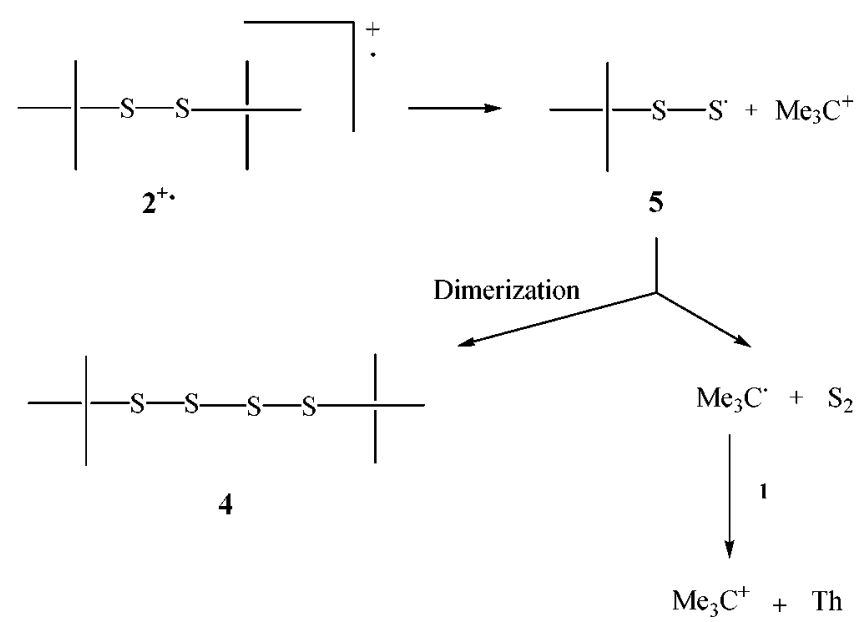

Scheme 2 


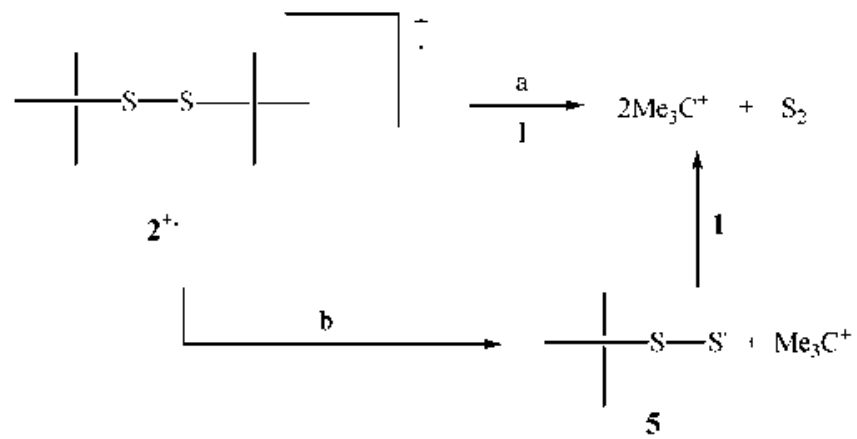

Scheme 3

dimerization of free 5 to 4 . The question of whether the rupture of the C-S bonds in $2 \%$ proceeds concertedly (a) or stepwise (b) can be debated (Scheme 3). A stepwise mechanism implies a radical intemediate 5. whereas a concerted reaction requires that fert-butyl cations and $\mathrm{S}_{2}$ be formed directly and at the same rate. Di-fert-butyl tetrasulplide (4) has shown promuse as a probe for differentiating stepwise (b) from concerted (a) mechanism in this reaction. In the oxidation of 5 . it has been found that 5 was not oxidized to fert-butylperthiyl cation directly but oxidized to tert-butyl cation via fert-butyl radical with evolution of $\mathrm{S}_{2}$ by C-S bond clearage. In support of the reluctant oxidation of 5 . it should be noted that the ionization potential (IP) of Th is near $7.90 \mathrm{eV}^{11.12}$ while the IP of 5 is $8.25 \mathrm{eV}^{9}$ Since Th has not enough oxidation potential $(1.3 \mathrm{~V})$ to oxidize 5 rapidly the small amounts of 5 can reasonably be expected to survive long enough to yield 4 .

If the Scheme 2 were the right reaction pathways. the reaction stoichiometry would not be $2.00: 1.00 \mathrm{1} / \mathbf{2}$. Careful. repeated five measurements of the ratio of reactants. made by adding $\mathbf{2}$ until the color of the $\mathbf{1}$ disappeared. showed that 1.78 mole of 1 was used per mole of 2 . As expected. we obtained a molar ratio of $2.00: 1.12 \mathbf{1 / 2}$. This ratio can be well adjusted by sulfur radicals escaping from oxidation and undergoing dimerization. In that case. more 2 would be needed for the reaction with unused 1 than required by oxidation with the ratio $2.00: 1.00$. The stoichiometric ratio found $2.00: 1.12$. says that $89.3 \%$ of tert-butyl groups were oxidized to carbocation which corresponds well with the $90 \%$ yield of tert-butyl cation-derived products. Control reaction of perclloric acid. $70 \%$ and 2 in MeCN was carried out to exclude all doubts of autocataly tic effects by trace acid generated from the electron transfer (ET) reaction. Quantitative amounts of starting disulfide. 2 were recovered. These observations indicate that the oxidative C-S cleavage of $\mathbf{2}$ is not catalyzed by the acid but is proceeded by ET mechanism exchusively:

In conclusion. a thermally stable disulfide has been shown to undergo facile oxidative $\mathrm{C}-\mathrm{S}$ bond cleavage instead of S-S rupture by cation radical at room temperature. In the oxidative decomposition of disulfide we have found unexpected dimerization product from the stable tert-butylperthiyl radical. The new reaction described herein can be expands the scope of oxidation of disulfides.

\section{Experimental Section}

Reaction of disulfide (2) with $\mathrm{Th}^{+\cdot} \mathrm{ClO}_{+}^{-}$(1). A general procedure was adopted. tert-Butyl disulfide (73.1 mg. 0.50 mmol) and $\mathrm{Th}^{\circ} \mathrm{ClO}_{1}{ }^{-}$(315 $\mathrm{mg} .1 .00 \mathrm{mmol}$ ) were placed in a $50 \mathrm{~mL}$ round-bottomed flask. containing a stirring magnet bar. and the flask was purged with dry argon after capping with a septum. Dry acetonitrile was introduced into the flask by syringe. and the dark purple color of 1 has disappeared. but the mixture was stirred overnight. Thereafter. $10 \mathrm{~mL}$ of water was added followed by aqueous $\mathrm{NaHCO}_{3}$ to neutralize $\mathrm{HClO}_{1}$ that had been formed in reaction. The solution was extracted with $3 \times 30 \mathrm{~mL}$ portions of methylene chloride. The methylene chloride solution was dried over $\mathrm{MgSO}_{n}$ and evaporated. The residue was dissolved in $10 \mathrm{~mL}$ of methy lene chloride. Portions of this solution were used for identification of products by $\mathrm{GC} / \mathrm{MS}$ and for quantitaitye analy sis by GC. The column used was a $2 \times 1 / 8$ in. stainless steel column packed with $10 \%$ OV- 101 on Chrom W. with naphthalene as an internal standard. Concentration factors for all products were determined with authentic materials.

tert-Butylacetamide $(3)^{13}$ was prepared as described in the literature.

\section{References and Notes}

1. Bac, D. II.: Fngel, P. S.: IIngue, A. K. M. M.: Keys. D. F.: I .ec. W. K.: Slaw, R. W.: Shinc. II. J. J. Am. Chem. Soc 1985, 107,2561 .

2. I.ce, W. K.: Chung. C. T. Bull Korew Chem. Soc. 1992, 13. 694

3. Chung. J. H.: Lim. S.-H.: Sohn. C. K.: Lee. W. K. Bull Korean (hem Soe 1998. 19.792.

4. I'ark. Y. S.: Lee. W. K. Bull Rovean Chem. Soc. 1997. /8. 360.

5. Choi, I. M. Ma. F.-K.: Solm. C. K.: I.ee, W. K. Bull Konem Chem. Soc 2000. 21, 1254.

6. Park. Y. S.: Hant. D. S.: J ce, W. K. Bull. Koned Chem. Soc. 1998. 19. 615

7. P'ark. B. K.: Sohn. C. K.: Lee. W. K. Bull. Korean Chem Sroc. 2002. 23. 103.

8. Whitham, G. II. In Organosulfur Chemismy: Oxtord Science Publications: 1995: p 25.

9. Sablicr, M: Fujii, T. Chem. Rev 2002. 102. 2855

10. Gerbatux. P.: Flammaner. R.: Pedersen. C. T.: Wong. M. W. J. Phys (hem. i. 1999. 103.3666.

11. Distelano. G.: Gallaso. V.: Iregolic. K. J.: Pappalardo. G. C. $J$. Chem. Soc. Perkin Trons. 2 1983. 1109.

12. Traven, V. F.: Redehenko, V. V.: Stepanow. B. I. Zh. Ohsch. Khim. $1981,51,129.3$

13. Ritter. J. J.: Minieri. P. P. J. . W. ('he'm. Soc. 1948. 70. 4045. 